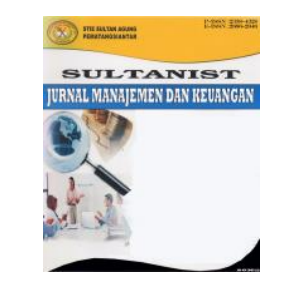

SULTANIST: Jurnal Manajemen dan Keuangan

Volume: 7 No: 2 Tahun 2019 Page (11-20)

ISSN: 2338-4328 (Print), ISSN: 2686-2646 (Online)

Available online at: https://sultanist.ac.id/index.php/sultanist

\title{
PENGARUH KOMUNIKASI INTERPERSONAL DAN KOMPENSASI TERHADAP KEPUASAN KERJA PADA PT PERKEBUNAN NUSANTARA III (PERSERO) KEBUN BANGUN
}

\author{
Yulia Pertiwi $^{1}$, Efendi ${ }^{2}$, Andy Wijaya ${ }^{3}$, Sudung Simatupang ${ }^{4}$ \\ Program Studi Manajemen, Sekolah Tinggi Ilmu Ekonomi Sultan Agung, \\ ypertiwi97@gmail.com \\ Program Studi Manajemen, Sekolah Tinggi Ilmu Ekonomi Sultan Agung, \\ efendi@stiesultanagung.ac.id, andywijaya@stiesultanagung.ac.id, \\ sudungsimatupang@stiesultanagung.ac.id
}

\begin{abstract}
Abstrak
Tingkat kepuasan kerja karyawan PT Perkebunan Nusantara III (Persero) Kebun Bangun masih belum optimal dilihat dari implementasi beberapa indikator yang belum maksimal. Tujuan penelitian ini adalah untuk mengetahui gambaran dan pengaruh komunikasi interpersonal, kompensasi dan kepuasan kerja karyawan pada PT Perkebunan Nusantara III (Persero) Kebun Bangun. Penelitian ini dilakukan dengan menggunakan desain penelitian, kepustakaan dan lapangan. Jenis data yang digunakan dalam penelitian ini adalah data kualitatif dan data kuantitatif. Sumber data adalah primer dan data sekunder. Populasi pada penelitian ini adalah sebanyak 50 orang dan seluruhnya merupakan karyawan tetap kantor PT Perkebunan Nusantara III (Persero) Kebun Bangun. Pengumpulan data dilakukan dengan kuesioner, wawancara dan dokumentasi. Teknik analisis yang digunakan adalah uji asumsi klasik, analisis deskriptif kualitatif dan deskriptif kuantitatif dengan linear berganda, analisis korelasi, koefisien determinasi dan uji hipotesis. Hasil penelitian menemukan $\mathrm{H}_{0}$ ditolak, artinya komunikasi interpersonal dan kompensasi berpengaruh positif dan signifikan terhadap kepuasan kerja karyawan pada PT Perkebunan Nusantara III (Persero) Kebun Bangun baik secara simultan maupun parsial.
\end{abstract}

Kata Kunci : Komunikasi Interpersonal, Kompensasi, Kepuasan Kerja.

\section{THE EFFECT OF INTERPERSONAL COMMUNICATION AND COMPENSATION ON WORK SATISFACTION IN PT PERKEBUNAN NUSANTARA III (PERSERO) KEBUN BANGUN}

\begin{abstract}
The level of job satisfaction of PT Perkebunan Nusantara III (Persero) Kebun Bangun employees is still not optimal as seen from the implementation of several indicators that have not been maximized. The purpose of this research is to determine the description and influence of Interpersonal Communication, Compensation and Satisfaction employee's at PT Perkebunan Nusantara III (Persero) Kebun Bangun either simultan or partially. This research was done by sing design of literature and field research. The type of data used in this research is qualitative and quantitative data. Sources of data are primary and secondary data. The population of this research are 50 people and all employee of PT Perkebunan Nusantara III (Persero) Kebun Bangun. Data was collected by questionnare, interview, documentation, and observation. The analysis technique used is the classical assumption test, qualitative descriptive and quantitative descriptive analysis with multiple linear regression, correlation analysis, determination coefficient and hypothesis testing. Research findings $H_{0}$ rejected, means interpersonal communication and compensation have a positive and significant impact on satisfaction performance at PT Perkebunan Nusantara III (Persero) Kebun Bangun either simultan or partially.
\end{abstract}

Keywords: Interpersonal Communication, Compensation, Work Satisfaction 


\section{SULTANIST: Jurnal Manajemen dan Keuangan, Vol 7 (2), 2019}

\section{PENDAHULUAN}

Manusia sebagai makhluk sosial pada dasarnya mempunyai sifat untuk berkomunikasi, berinteraksi dan bersosialisasi dengan manusia lainnya. Untuk itu keberadaan suatu organisasi diharapkan dapat menjadi wadah yang menghimpun anggotanya untuk berkomunikasi, berinteraksi dan bersosialisasi dengan pimpinan maupun dengan rekan kerja dalam organisasi tersebut. PT Perkebunan Nusantara III (Persero) Kebun Bangun adalah salah satu Badan Usaha Milik Negara (BUMN) yang bergerak di sektor perkebunan dengan mengelola tanaman budidaya kelapa sawit dan karet. PT Perkebunan Nusantara III (Persero) Kebun Bangun yang bergerak dalam usaha perkebunan kelapa sawit dan karet. Karyawan sebagai sumber daya manusia yang bekerja di dalamnya terdiri dari beragam sifat dan karakter yang berbeda-beda.

Adapun dimensi kepuasan kerja pada PT Perkebunan Nusantara III (Persero) Kebun Bangun yaitu pekerjaan itu sendiri, kesempatan promosi, mutu pengawasan supervisi, rekan kerja, dan kondisi. Tingkat kepuasan kerja karyawan PT Perkebunan Nusantara III (Persero) Kebun Bangun masih belum optimal. Dimana masih ada persentase dengan kategori tidak puas sebesar 6\%. Fenomena kepuasan kerja terdiri dari mutu pengawasan supervisi dan kondisi kerja. Pada dimensi mutu pengawasan supervisi, walaupun terdapat prosedur pengawasan tetapi pimpinan belum maksimal dalam menjalankan pengawasan tersebut. Selanjutnya pada dimensi kondisi kerja, dikarenakan karyawan merasa kurang nyaman dengan kondisi lingkungan kerja seperti ada beberapa ruang kerja yang tidak memiliki pendingin ruangan.
Salah satu faktor yang mempengaruhi kepuasan kerja adalah komunikasi interpersonal. Hal ini sesuai dengan pendapat Sutrisno (2011:77), faktor-faktor yang mempengaruhi kepuasan kerja adalah kesempatan untuk maju, keamanan kerja, gaji, perusahaan dan manajemen, pengawasan, faktor instrinsik dari pekerjaan, kondisi kerja, aspek sosial dalam pekerjaan, komunikasi dan fasilitas. Dimensi komunikasi interpersonal dapat dilihat dari bakat, minat dan kepribadian. Adapun fenomena yang terjadi pada dimensi minat ialah kurangnya kemauan karyawan dalam mengembangkan potensi yang ada pada dirinya. Sedangkan fenomena kepribadian masih terdapat beberapa karyawan yang kurang optimal, dimana kurang akrab hubungan antar karyawan yang ada di setiap ruangan direksi.

Faktor lain yang mempengaruhi kepuasan kerja adalah kompensasi. Menurut Mathis dan John (2011:419), kompensasi merupakan faktor penting yang mempengaruhi bagaimana dan mengapa orang-orang memilih untuk bekerja di sebuah organisasi dari pada organisasi yang lain. Adapun dimensi kompensasi yaitu kompensasi finansial yang berupa upah, gaji, insentif, dan bonus, dan kompensasi non finansial seperti tunjangan karyawan yang berupa asuransi kesehatan, asuransi jiwa, bantuan perumahan, fasilitas kantor, kenyamanan serta kelengkapan pakaian kerja.

Dalam dimensi kompensasi finansial di PT Perkebunan Nusantara III (Persero) Kebun Bangun tidak terlihat adanya fenomena, namun dalam dimensi kompensasi non finansial terdapat fenomena, yaitu terjadi pada akses asuransi kesehatan yang masih terkendala dengan rumah sakit yang harus ke luar kota untuk mendapatkan asuransi kesehatan. Serta 


\section{SULTANIST: Jurnal Manajemen dan Keuangan, Vol 7 (2), 2019}

terdapat fenomena dalam bantuan perumahan yang karyawan dapatkan masih ada kondisi perumahan yang sebaiknya dapat diperbaiki.

Tujuan penelitian adalah untuk mengetahui gambaran dan pengaruh komunikasi interpersonal dan kompetensi terhadap kepuasan kerja karyawan di PT Perkebunan Nusantara III (Persero) Kebun Bangun baik secara simultan maupun parsial.

\section{LANDASAN TEORI}

\section{Manajemen dan Manajemen Sumber Daya Manusia}

Pencapaian tujuan organisasi pada umumnya memiliki manajemen yang baik. Pelaksanaan manajemen dianggap penting agar tujuan organisasi dapat tercapai. Menurut Terry dan Leslie (2010), manajemen merupakan proses perencanaan, pengorganisasian, proses pergerakan dan pengendalian sumber daya manusia dan sumber daya lainnya. Selanjutnya manajemen sumber daya manusia merupakan bagian manajemen umum yang meliputi perencanaan, pengorganisasian, pelaksanaan dan pengendalian (Zainal dkk, 2015)

\section{Komunikasi Interpersonal}

Dalam perusahaan atau organisasi proses komunikasi antara individu sering terjadi sebagai salah bentuk interaksi antara kedua individu. Menurut Luthans (2006:380), "komunikasi interpersonal merupakan suatu proses pengiriman informasi dari satu orang ke orang lain. Komunikasi dilihat sebagai metode dasar yang mempengaruhi perubahan perilaku, dan komunikasi menghubungkan proses psikologi (persepsi, pembelajaran dan motivasi) pada satu sisi dan bahasa pada sisi lainnya". Menurut Mathis dan John (2011), ada tiga faktor yang mendukung keberhasilan komunikasi interpersonal, yaitu: bakat, minat dan kepribadian.

\section{Kompensasi}

Hasil kerja yang optimal dan sesuai dengan kriteria organisasi tentunya akan memberikan umpan balik dalam bentuk upah yang sesuai kuantitas dan kualitas. Menurut Bangun (2012:255), "kompensasi merupakan imbalan yang dibayarkan kepada karyawan atas jasa yang mereka sumbangkan pada pekerjaannya”. Komponen-komponen kompensasi pada umumnya terdiri atas dua yaitu kompensasi finansial dan kompensasi non finansial (Mondy, 2008).

\section{Kepuasan Kerja}

Setiap individu yang bekerja dalam organisasi tentunya pernah mengalami keadaan dimana merasa puas atas hasil dari pekerjaan yang dilakukan. Menurut Sutrisno (2011:74), "kepuasan kerja yaitu suatu sikap karyawan terhadap pekerjaan yang berhubungan dengan situasi kerja, kerja sama antar karyawan, imbalan yang diterima dalam kerja, dan hal-hal menyangkut faktor fisik dan psikologis". Selanjutnya untuk dimensi kepuasan kerja meliputi: pekerjaan itu sendiri, gaji, kesempatan promosi, pengawasan, rekan kerja, dan kondisi kerja (Luthans, 2006).

\section{Pengaruh Komunikasi Interpersonal Terhadap Kepuasan Kerja}

Menurut Sutrisno (2011:77), faktorfaktor yang mempengaruhi kepuasan kerja adalah kesempatan untuk maju, keamanan kerja, gaji, perusahaan dan manajemen, pengawasan, faktor instrinsik dari pekerjaan, kondisi kerja, aspek sosial dalam pekerjaan, komunikasi dan fasilitas. Hal ini sejalan dengan penelitian yang dilakukan Hidayat, Roni dan Lutfi (2012), Paramitha dan Luh Made (2018), Muruf (2016), Nadeak (2017) yang menyatakan bahwa terdapat pengaruh 
antara komunikasi interpersonal terhadap kepuasan.

\section{Pengaruh Kompensasi terhadap Kepuasan Kerja.}

Menurut Mathis dan John (2011:419), kompensasi merupakan faktor penting yang mempengaruhi bagaimana dan mengapa orang-orang memilih untuk bekerja di sebuah organisasi dari pada organisasi yang lain. Para pemberi kerja harus kompetitif dengan beberapa jenis kompensasi untuk menarik dan mempertahankan karyawan yang kompeten. Hal ini merupakan kebutuhan yang mendasar apabila pegawai bekerja dalam sebuah perusahaan, baik berupa gaji/upah, insentif, komisi, pujian, motivasi dan bonus. Agar kepuasan kerja pegawai semakin meningkat. Hal ini sejalan dengan penelitian yang dilakukan Riansari, Achmad dan Rofiaty (2012), Agathanisa dan Arif (2018), Al Qofiqi, Bambang dan Ika (2016), Nugraha dan Ida (2016) yang menyatakan bahwa terdapat pengaruh antara kompensasi terhadap kepuasan.

\section{METODE PENELITIAN}

Dalam penelitian ini, penulis menggunakan desain penelitian kepustakaan dan lapangan. Objek penelitian adalah karyawan PT Perkebunan Nusantara III (Persero) Kebun Bangun, tempat penelitian dilakukan pada PT Perkebunan Nusantara III (Persero) Kebun Bangun. Jenis data yang digunakan adalah data kualitatif dan kuantitatif dan sumber data berasal dari data primer dan data sekunder. Data penelitian dikumpulkan dengan melakukan wawancara, dokumentasi dan penyebaran kuesioner. Analisis data meliputi analisis data kualitatif dan analisis kuantitatif.

\section{PEMBAHASAN}

\section{Analisis Deskriptif Kualitatif}

Analisis deskriptif dimaksudkan untuk mendapatkan gambaran komunikasi interpersonal, kompensasi terhadap kepuasan kerja karyawan pada PT Perkebunan Nusantara III (Persero) Kebun Bangun. Adapun penetapan kriteria nilai rata-rata jawaban responden tersebut dimasukkan ke dalam kelas-kelas interval berikut:

Tabel 1. Nilai Interval dan Kategori Jawaban Responden

\begin{tabular}{|c|c|}
\hline $\begin{array}{c}\text { Nilai } \\
\text { interval }\end{array}$ & Kategori \\
\hline $1,00-1,80$ & $\begin{array}{c}\text { Sangat Tidak Baik/ Sangat Tidak } \\
\text { Puas }\end{array}$ \\
\hline $1,81-2,60$ & Tidak Baik/Tidak Puas \\
\hline $2,61-3,40$ & Cukup Baik/Cukup Puas \\
\hline $3,41-4,20$ & Baik/Puas \\
\hline $4,21-5,00$ & Sangat Baik/Sangat Puas \\
\hline
\end{tabular}

Sumber: hasil pengolahan data (2019)

\section{Gambaran Komunikasi Interpersonal pada PT Perkebunan Nusantara III (Persero0 Kebun Bangun}

Secara keseluruhan dapat dilihat bahwa untuk total jawaban responden mengenai komunikasi interpersonal mendapat nilai rata-rata 4,01 dengan kriteria jawaban sangat baik kemudian nilai rata-rata tinggi 4,32 untuk dimensi kepribadian pada indikator kemampuan bersepakat pada sesama rekan kerja, sedangkan nilai rata-rata terendah sebesar 3,24 untuk dimensi kepribadian pada indikator interaksi manajer kepada karyawan.

\section{Gambaran Kompensasi pada PT Perkebunan Nusantara III (Persero) Kebun Bangun}

Secara keseluruhan dapat dilihat bahwa untuk total jawaban responden mengenai kompensasi 3,9 dengan kriteria jawaban baik. Nilai rata-rata tertinggi sebesar 4,22 dengan kriteria jawaban sangat baik berada pada dimensi kompensasi finansial terdapat 
pada indikator asuransi. Sedangkan nilai rata-rata terendah sebesar 3,3 dengan kriteria cukup baik terdapat pada dimensi kompensasi non finansial dengan indikator bantuan perumahan dan akses asuransi kesehatan.

\section{Gambaran Kepuasan Kerja Karyawan PT Perkebunan Nusantara III (Persero) Kebun Bangun}

Secara keseluruhan kepuasan kerja karyawan dengan dimensi pekerjaan itu sendir, kesempatan promosi, mutu pengawasan supervisi, rekan kerja dan kondisi kerja memiliki nilai rata-rata 4,02 dengan kriteria jawaban puas. Kemudian nilai rata-rata tertinggi pada indikator dukungan dari rekan kerja memiliki nilai rata-rata 4,34 dengan kriteria jawaban sangat puas. Sedangkan nilai rata-rata terendah pada indikator pengawasan terhadap kepuasan karyawan dan indikator ketersediaan fasilitas kerja memiliki nilai rata-rata 3,24 yang kriteria cukup puas.

\section{Analisis Deskriptif Kuantitatif}

\section{Analisis Regresi Linier Berganda}

Untuk menganalisa pengaruh Komunikasi Interpersonal $\left(\mathrm{X}_{1}\right)$ dan Kompensasi $\left(\mathrm{X}_{2}\right)$ terhadap Kepuasan Kerja (Y) pada PT Perkebunan Nusantara III (Persero) Kebun Bangun secara bersamasama digunakan bantuan program SPSS versi 21 pada berikut ini:

\section{Tabel 2. Hasil Regresi Linear Berganda} Coefficients $^{a}$

\begin{tabular}{|l|r|r|r|}
\hline Model & \multicolumn{2}{|c|}{$\begin{array}{c}\text { Unstandardized } \\
\text { Coefficients }\end{array}$} & $\begin{array}{c}\text { Standardized } \\
\text { Coefficients }\end{array}$ \\
\cline { 2 - 4 } & \multicolumn{1}{|c|}{ B } & Std. Error & \multicolumn{1}{c|}{ Beta } \\
\hline (Constant) & 23.867 & 5.239 & \\
$1 \begin{array}{l}\text { Komunikasi } \\
\text { Interpersonal }\end{array}$ &, 524 &, 178 &, 390 \\
Kompensasi &, 504 &, 167 &, 401
\end{tabular}

a. Dependent Variable: Kepuasan Kerja

Sumber: hasil pengolahan data (2019)

Dari hasil regresi dengan SPSS versi 21 pada tabel diperoleh koefisien regresi $b_{1}$ sebesar 0,524 dan $b_{2}$ sebesar 0,504 sehingga dapat diketahui persamaan regresi yang di peroleh adalah $\hat{\mathrm{Y}}=23,867+0,524 \mathrm{X}_{1}+$ $0,504 \mathrm{X}_{2}$, artinya terdapat pengaruh yang positif antara Komunikasi Interpersonal $\left(\mathrm{X}_{1}\right)$ dan Kompensasi $\left(\mathrm{X}_{2}\right)$ terhadap (Y) pada PT Perkebunan Nusantara III (Persero) Kebun Bangun.

\section{Analisis Korelasi dan Koefisien Determinan (KD)}

Untuk mengetahui kekuatan hubungan Komunikasi Interpersonal dan Kompensasi terhadap Kepuasan Kerja dilakukan analisis korelasi, berupa derajat atau kedalaman hubungan fungsional yang menjelaskan hubungan antar nilai $r$. Nilai $r$ dapat dilihat melalui tabel berikut:

\section{Tabel 3. Koefisien Korelasi dan Koefisien Determinasi} Model Summary ${ }^{b}$

\begin{tabular}{|c|c|c|c|c|}
\hline $\begin{array}{c}\text { Mod } \\
\text { el }\end{array}$ & $\mathbf{R}$ & $\begin{array}{c}\mathbf{R} \\
\text { Square }\end{array}$ & $\begin{array}{l}\text { Adjusted } \\
\text { R Square }\end{array}$ & Std. Error of the Estimate \\
\hline 1 & $.717^{\mathrm{a}}$ & .514 & .494 & 4.505 \\
\hline
\end{tabular}

Sumber: hasil pengolahan data (2019)

Dari hasil analisis regresi dengan SPSS pada tabel 3 di atas, didapat korelasi sebesar $r=0,717$ yang artinya terdapat hubungan yang kuat dan positif antara komunikasi interpersonal dan kompensasi terhadap kepuasan kerja PT Perkebunan Nusantara III (Persero) Kebun Bangun. Koefisien determinasi 0,514 artinya baik tidaknya kepuasan kerja dapat dijelaskan sebesar $51,4 \%$ oleh komunikasi interpersonal dan kompensasi selebihnya 48,6\% dijelaskan oleh faktor-faktor lain seperti kepemimpinan, motivasi, kemampuan dan lain-lain.

\section{Uji Hipotesis}

Pengujian ini dilakukan secara simultan yaitu dilakukan untuk menentukan diterima 
atau ditolaknya hipotesis, pengujian hipotesis dilakukan untuk mengetahui apakah variabel Komunikasi Interpersonal dan Kompensasi yang di uji berpengaruh terhadap Kepuasan Kerja jika $F_{\text {hitung }}>F_{\text {tabel }}$ signifikan $\leq 0,05$ maka $\mathrm{H}_{0}$ ditolak. Dengan menggunakan bantuan program SPSS versi 21, didapatkan hasil perhitungan $F_{\text {hitung }}$ sebagai berikut:

\section{Tabel 4. Perkiraan Nilai $F_{\text {hitung }}$}

\begin{tabular}{|c|c|c|c|}
\hline Model & $\begin{array}{l}\text { Sum of } \\
\text { Squares }\end{array}$ & $\mathrm{F}$ & Sig \\
\hline Regression & 1010.671 & 24.900 & $.000^{b}$ \\
\hline Residual & 953.829 & & \\
\hline Total & 1964.500 & & \\
\hline
\end{tabular}

Sumber: hasil pengolahan data (2019)

Berdasarkan tabel di atas, diperoleh

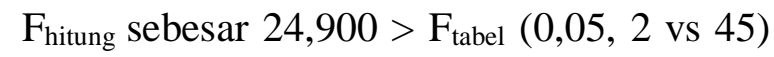
sebesar 3,20 atau dengan taraf signifikan $0,000<\alpha$ berpengaruh positif dan signifikan terhadap kepuasan kerja karyawan pada PT Perkebunan Nusantara III (Persero) Kebun Bangun.

Pengujian selanjutnya adalah uji t. Pengujian ini dilakukan secara parsial yaitu untuk menentukan diterima atau ditolaknya hipotesis, pengaruh hipotesis dilakukan untuk mengetahui apakah variabel Komunikasi Interpersonal dan Kompensasi yang di uji berpengaruh terhadap Kepuasan Kerja jika $t_{\text {hitung }}>t_{\text {tabel }}$ signifikan $\alpha \leq 0,05$ maka $\mathrm{H}_{0}$ ditolak. Untuk menguji kebenarannya maka dilakukan pengujian hipotesis dengan menggunakan program SPSS versi 21.

Tabel 5. Perkiraan nilai $t_{\text {hitung }}$

\begin{tabular}{|c|c|c|}
\hline \multicolumn{3}{|c|}{ Coefficients $^{\boldsymbol{a}}$} \\
\hline Model & $\mathrm{t}$ & $\mathrm{Sig}$ \\
\hline Constant & 4.556 & \\
\hline Komunikasi & $\mathbf{2 . 9 4 2}$ & $\mathbf{0 . 0 0 0}$ \\
Interpersonal & & \\
\hline Kompensasi & $\mathbf{3 . 2 0 7}$ & $\mathbf{0 . 0 0 0}$ \\
\hline
\end{tabular}

Sumber: hasil pengolahan data (2019)
Berdasarkan tabel 5 di atas dapat dilihat $\mathrm{t}_{\text {hitung }}$ pada variabel Konunikasi $\left(\mathrm{X}_{1}\right)$ sebesar $2,942>\mathrm{t}_{\text {tabel }}$ dengan $\mathrm{df}=\mathrm{n}-\mathrm{k}-1(50-2-1)$ artinya 2,011 atau taraf signifikansi $0,005 \leq$ a 0,05 maka $\mathrm{H}_{0}$ ditolak, artinya komunikasi interpersonal berpengaruh positif dan signifikan terhadap kepuasan kerja karyawan pada PT Perkebunan Nusantara III (Persero) Kebun Bangun.

Sedangkan thitung pada variabel kompensasi $\left(\mathrm{X}_{2}\right)$ sebesar 3,024 dan $t_{\text {tabel }}$ dengan df $=n-k-1(50-2-1)$ sebesar 2,011 atau dengan taraf signifikansi $0,004 \leq$ $\alpha$ 0,05 maka $\mathrm{H}_{0}$ ditolak, artinya kompensasi berpengaruh positif dan signifikan terhadap kepuasan kerja karyawan pada PT Perkebunan Nusantara III (Persero) Kebun Bangun.

\section{Evaluasi}

\section{Komunikasi Interpersonal Pada PT Perkebunan III (Persero) Kebun Bangun}

Komunikasi interpersonal merupakan komunikasi bila dilakukan oleh dua orang maka satu orang menjadi komunikator dan satu orang lainnya menjadi komunikan. Dan adanya respon dalam setiap komunikasi tanpa adanya hambatan-hambatan. Berdasarkan ketiga dimensi di atas terdapat beberapa indikator pada komunikasi interpersonal yang digunakan dan hasil penelitian yang diperoleh maka dapat dijelaskan bahwa komunikasi interpersonal yang diterapkan pada PT Perkebunan Nusantara III (Persero) Kebun Bangun dapat dikatakan baik, hal ini dapat dibuktikan dengan nilai rata-rata 4,01 dengan kriteria jawaban baik.

Dari nilai rata-rata di atas, ada dimensi yang perlu diperhatikan seperti minat. Dimens minat pada indikator kemauan dengan nilai rata-rata 3,3 dengan kriteria cukup baik. Untuk meningkatkannya kayawan harus lebih berpotensi untuk 


\section{SULTANIST: Jurnal Manajemen dan Keuangan, Vol 7 (2), 2019}

mengembangkan potensi yang ada pada dirinya. Pada dimensi kepribadian dengan indikator interaksi dengan rata-rata 3,24 dengan kriteria jawaban cukup baik. Untuk mengatasinya karyawan harus lebih jelas dan terarah memberkan intruksi kepada karyawan lainnya.

Dari evaluasi komunikasi interpersonal di atas dapat disimpulkan bahwa semua dimensi-dimensi sudah berada pada nilai rata-rata dengan kriteria yang baik. Hal ini menunjukkan bahwa karyawan sudah cukup baik dalam melakukan komunikasi dengan atasan maupun dengan rekan kerja. Namun, apabila beberapa hal diatas dapat diatasi dan ditingkatkan lagi, tentunya akan memberikan manfaat yang lebih baik kepada karyawan serta dapat meningkatkan kepuasan karyawan.

\section{Kompensasi Pada PT Perkebunan Nusantara III (Persero) Kebun Bangun}

Berdasarkan hasil yang diperoleh dari kedua dimensi yang digunakan dalam penelitian ini, hasil yang diperoleh dapat dijelaskan bahwa kompensasi yang diberikan oleh PT Perkebunan Nusantara III (Persero) Kebun Bangun dapat dikatakan baik dari dimensi kompensasi finansial dan kompensasi non finansial. Hal ini dibuktikan berdasarkan hasil kuesioner yang diperoleh nilai rata-rata 3,9 dengan kriteria jawaban baik. Namun masih terdapat beberapa indikator yang nilainya dibawah rata-rata keseluruhan yang perlu menjadi perhatian pihak PT Perkebunan Nusantara III (Persero) Kebun Bangun dan dapat diperbaiki untuk meningkatkan kepuasan karyawan dikemudian hari.

Pada dimensi kompensasi non finansial dengan indikator bantuan perumahan berada pada nilai rata-rata 3,3 dengan kriteria jawaban cukup baik. Hal ini dapat diperbaiki dengan cara sebaiknya perusahaan memperbaiki perumahan karyawan agar karyawan merasa nyaman. Pada indikator akses asuransi kesehatan berada pada nilai rata-rata 3,3 dengan kriteria jawaban cukup baik. Hal ini dapat diperbaiki dengan cara sebaiknya perusahaan dapat bekerjasama dengan pihak rumah sakit di daerah setempat supaya karyawan yang membutuhkan perawatan dirumah sakit.

Dari evaluasi kompensasi di atas dapat disimpulkan bahwa semua dimensi-dimensi sudah berada pada nilai rata-rata dengan kriteria yang baik. Hal ini menunjukkan bahwa perusahaan sudah cukup baik dalam memberikan timbal balik kepada karyawan perusahaan. Namun, apabila beberapa hal diatas dapat di atasi dan ditingkatkan lagi, tentunya akan memberikan manfaat yang lebih baik kepada karyawan serta dapat meningkatkan kepuasan karyawan.

\section{Kepuasan Kerja Pada PT Perkebunan Nusantara III (Persero) Kebun Bangun}

Kepuasan kerja merupakan hal yang bersifat individual. Setiap individu memiliki tingkat kepuasan yang berbeda-beda. Dimensi kepuasan kerja karyawan pada PT Perkebunan Nusantara III (Persero) Kebun Bangun bisa dikatakan baik, hal ini dapat dilihat dari hasil kuesioner yang dibagi kepada responden secara keseluruhan memperoleh nilai rata-rata 4,02 berdasarkan nilai rata-rata di atas, terdapat beberapa dimensi di bawah rata-rata walaupun sudah dikatakan kriteria baik.

Pada dimensi pekerjaan itu sendiri dengan indikator pekerjaan yang diberikan kepada karyawan memiliki nilai rata-rata 3,9 dengan kriteria jawaban baik. Hal ini dapat ditingkatkan dengan cara sebaiknya pimpinan memberikan pekerjaan yang sesuai dengan kemampuan karyawan 


\section{SULTANIST: Jurnal Manajemen dan Keuangan, Vol 7 (2), 2019}

sehingga karyawan nyaman dalam menyelesaikan pekerjaannya.

Pada dimensi promosi dengan indikator promosi berdasarkan lama bekerja memperoleh nilai rata-rata 3,92 dengan kriteria puas. Hal ini dapat ditingkatkan dengan cara sebaiknya perusahaan meningkatkan promosi berdasarkan lama bekerja agar karyawan yang memiliki masa kerja paling lama termotivasi untuk bekerja dengan baik dan perlu diberi penghargaan dan kemampuan yang dimilikinya, pengalaman yang lebih banyak, ide-ide yang kreatif, dan tingkat pendidikan yang baik supaya bisa dipromosikan didalam suatu perusahaan. Maka pihak PT Perkebunan Nusantara III (Persero) Kebun Bangun harus memberikan reward serta kenaikan jabatan untuk karyawan yang sudah lama bekerja di PT Perkebunan Nusantara III (Persero) Kebun Bangun.

Pada dimensi mutu pengawasan mutu pengawasan supervise dengan indikator pengawasan terhadap karyawan memiliki nilai rata-rata 3,24 dengan kriteria jawaban cukup puas. Hal ini dapat ditingkatkan dengan cara sebaiknya pimpinan harus lebih menegakkan disiplin dan dipantau dalam beberapa kesempatan tanpa diketahui oleh karyawan, pemantauan ini untuk melihat bagaimana karyawan menunjukkan sikap kerjanya setiap hari bahkan setiap saat. Dari sinilah pimpinan bisa menggambarkan atau menilai kinerjanya.

Pada dimensi kondisi kerja dengan indikator suasana kerja yang kondusif memiliki nilai rata-rata 3,92 dengan kriteria jawaban puas. Hal ini harus tetap dipertahankan dan ditingkatkan lagi supaya para karyawan PT Perkebunan Nusantara III (Persero) Kebun Bangun terus merasa nyaman dalam mengerjakan pekerjaan mereka. Pada indikator fasilitas yang diberikan perusahaan berada pada nilai rata- rata 3,24 dengan kategori jawaban cukup puas. Hal ini dapat dapat ditingkatkan dengan cara penambahan berbagai fasilitas kantor guna untuk membantu para karyawan mempercepat pekerjaannya.

Dari evaluasi kepuasan dapat disimpulkan bahwa semua dimensi-dimensi diatas sudah berada pada nilai rata-rata dengan kriteria yang puas. Hal ini menunjukkan bahwa sebenarnya perusahaan sudah cukup baik dalam hal kepuasan kerja. Namun, apabila beberapa hal di atas dapat di atasi dan ditingkatkan lagi, tentunya akan memberikan manfaat yang lebih baik kepada perusahaan.

\section{KESIMPULAN DAN SARAN}

\section{Kesimpulan}

Hasil analisis regresi linear berganda menunjukkan adanya pengaruh positif antara variabel komunikasi interpersonal dan kompensasi terhadap kepuasan kerja karyawan pada PT Perkebunan Nusantara III (Persero) Kebun Bangun. Hasil analisis korelasi terdapat hubungan yang kuat dan positif antara komunikasi interpersonal dan kompensasi terhadap kepuasan kerja karyawan pada PT Perkebunan Nusantara III (Persero) Kebun Bangun. Kemudian analisis koefisien determinasi menunjukkan bahwa tinggi rendahnya kepuasan kerja karyawan (Y) pada PT Perkebunan Nusantara III (Persero) Kebun Bangun dapat dijelaskan pada komunikasi interpersonal $\left(\mathrm{X}_{1}\right)$ dan kompensasi $\left(\mathrm{X}_{2}\right)$.

Hasil pengujian hipotesis dengan Uji $\mathrm{F}$ (uji simultan) diperoleh $\mathrm{F} \mathrm{H}_{0}$ ditolak, artinya terdapat pengaruh positif dan signifikan antara variabel komunikasi interpersonal dan kompensasi terhadap kepuasan kerja karyawan pada PT Perkebunan Nusantara III (Persero) Kebun Bangun. Hasil pengujian hipotesis dengan Uji t (uji parsial) diperoleh $\mathrm{H}_{0}$ ditolak, artinya terdapat 
pengaruh positif dan signifikan antara komunikasi interpersonal dan kompensasi terhadap kepuasan kerja karyawan pada PT Perkebunan Nusantara III (Persero) Kebun Bangun secara parsial.

\section{Saran}

Untuk meningkatkan komunikasi interpersonal pada PT Perkebunan Nusantara III (Persero) Kebun Bangun sangat penting karena masih ada beberapa indikator belum optimal. Sebaiknya pimpinan lebih sering berinteraksi kepada karyawan supaya karyawan merasa nyaman ketika ada atau tidaknya pimpinan di kantor. Selanjutnya untuk kompensasi perlu diperbaiki, karena terdapat indikator yang masih belum optimal, untuk itu sebaiknya perusahaan lebih memperhatikan kebutuhan karyawan seperti perumahan yang sudah rusak untuk diperbaiki, dan akses untuk ke rumah sakit ketika karyawan ingin memeriksa kesehatan dan membeli obatobatan supaya diadakan di daerah karyawan bertempat tinggal. Untuk meningkatkan kepuasan kerja pada PT Perkebunan Nusantara III (Persero) Kebun Bangun masih ada yang perlu ditingkatkan karena masih ada indikator yang belum optimal. Untuk mengoptimalkan kepuasan kerja karyawan sebaiknya seorang pimpinan meningkatkan pengawasan terhadap karyawan supaya memaksimalkan pekerjaan karyawan. Serta perusahaan sebaiknya memperhatikan kebutuhan karyawan di kantor dengan memenuhi fasilitas yang cukup yang sesuai dengan standar.

\section{DAFTAR PUSTAKA}

Al Qofiqi, Mohammad Nizar, Bambang Swasto Sunuharjo dan Ika Ruhana. 2016. Pengaruh Kompensasi Terhadap Kepuasan Kerja dan Intention to Leave (Studi Pada Karyawan Bank Jatim Cabang Malang). Jurnal Adminitrasi Bisnis. 37(2), 121127.
Agathanisa, Citha dan Arif Partono Prasetio. 2018. Pengaruh Kompensasi Terhadap Kepuasan Kerja Karyawan Indogrosir Samarinda. Jurnal Mitra Manajemen. 2(4), 308-319.

Bangun. Wilson. 2012. Manajemen Sumber Daya Manusia. Jakarta: Erlangga.

Hidayat, Rohmat, Roni Kambara dan Lutfi.

2018. Pengaruh Motivasi

Intrinsik, Komunikasi

Interpersonal dan Kepemimpinan

Transformasional Terhadap

Kepuasan Kerja Dalam

Meningkatkan Kinerja Pegawai.

Jurnal Riset Bisnis dan Manajemen Tirtayasa. 2(1), 4366.

Luthans, Fred. 2006. Perilaku Organisasi. Edisi X. Yogyakarta: ANDI.

Mathis, Robert L. dan John H. Jackson, 2006. Human Resourch

Management. Edisi 10. Jakarta: Salemba Empat.

Muruf, Yudie Damar. 2016. Pengaruh Pelatihan Komunikasi Interpersonal Terhadap Kepuasan Relasi dengan Rekan Kerja Pada Guru. Jurnal Ilmiah Psikologi. 18(1), 92-108.

Nadeak, Banuara. 2017. Pengaruh Locus Of Control, Integritas, dan Komunikasi Interpersonal Terhadap Kepuasan Kerja PNS DISDIPORA Karawang. Prosiding Seminar Nasional Multi Disiplin Ilmu. (3). 480-486.

Nugraha, Made Bayu Indra dan Ida Bagus Ketut Surya. Pengaruh Kompensasi, Lingkungan Kerja dan Promosi Jabatan Terhadap Kepuasan Kerja. E-Jurnal Manajemen Unud. 5(1), 59-87.

Paramita, Ni Kadek Pradnya dan Luh Made Karisma Sukmayati Suarya. 2018. 
Peran Komunikasi Interpersonal dan Ekspresi Emosi Terhadap Kepuasan Perkawinan Pada Perempuan di Usia Dewasa Madya. Jurnal Psikologi Udayana. Edisi Khusus, 16-28.

Riansari, Titi, Achmad Sudiro dan Rofiaty. 2012. Pengaruh Kompensasi dan Lingkungan Kerja Terhadap Kepuasan Kerja dan Kinerja Karyawan (Studi Kasus PT Bank Tabungan Pensiunan Nasional, Tbk Cabang Malang). Jurnal Aplikasi Manajemen. 10 (4), 811-820.

Sutrisno, Edy. 2011. Manajemen Sumber Daya Manusia. Edisi Pertama Cetakan Pertama. Jakarta: Penerbit Kencana Prenada Media Group.

Terry, George dan Leslie W. Rue. 2010. Dasar-Dasar Manajemen. Cetakan 11. Jakarta: Bumi Aksara.

Zainal, dkk. 2015. Manajemen Sumber Daya Manusia Untuk Perusahaan. Cetakan 7, Edisi III. Jakarta: Rajawali Press.

\section{Profil Singkat}

Yulia pertiwi, Lahir di Sahkuda Bayu, tanggal 25 Juli 1997, lulus dari jurusan Sarjana Manajemen Sekolah Tinggi Ilmu Ekonomi Sultan Agung pada tahun 2019. Efendi, gelar magister manajemen diperoleh dari Program Magister Manajemen Fakultas Pascasarjana Universitas HKBP Nommensen Medan dan lulus pada tahun . Gelar doktor diperoleh dari Universitas Pasundan Bandung dengan konsentrasi ilmu manajemen dan lulus pada tahun 2018. Andy Wijaya, gelar magister manajemen diperoleh dari Program Magister Manajemen Fakultas Pascasarjana Universitas HKBP Nommensen Medan dan lulus pada tahun 2013. Sudung Simatupang, gelar magister manajemen diperoleh dari Program Magister Manajemen Fakultas Pascasarjana Universitas HKBP Nommensen Medan dan lulus pada tahun 2014. 